\title{
Morphological Traits Study of Three Indigenous Poultry in Nigeria
}

\author{
Uhenna D. Abazuh ${ }^{1 *}$, Khalid O. Adekoya ${ }^{2}$ and Bola O. Oboh ${ }^{2}$ \\ ${ }^{1}$ Department of Biological Science, College of Natural Sciences, Redeemer's University, \\ Ede, Osun State, Nigeria. \\ ${ }^{2}$ Department of Cell Biology and Genetics, Faculty of Sciences, University of Lagos, Lagos, Nigeria.
}

Authors' contributions

This work was carried out in collaboration among all authors. Authors UDA, KOA and BOO designed the study. Author UDA performed the statistical analysis. Authors UDA, KOA and BOO wrote the protocol. Author UDA wrote the first draft of the manuscript, managed the analyses of the study and literature searches. All authors read and approved the final manuscript.

Article Information

DOI: $10.9734 / A R R B / 2019 /$ v34i530167 Editor(s):

(1) Dr. Jean-Marie Exbrayat, Universite Catholique de Lyon, France. (2) Professor, George Perry, University of Texas at San Antonio, USA. Reviewers: (1) Wafaa Abd El-Ghany, Cairo University, Egypt. (2) Idowu Peter Ayodeji, University of Fort Hare, South Africa. Complete Peer review History: http://www.sdiarticle4.com/review-history/48045

Original Research Article

Received 28 January 2019

Accepted 01 April 2019

Published 05 March 2020

\begin{abstract}
Aim: This study investigated relatedness among three indigenous chicken types using morphological features and morphological trait interdependence within three indigenous poultry species in Nigeria.

Study Design: A complete Random sample design was employed in this study to investigate morphological relatedness.

Place and Duration of the Study: Birds of reproductive age were sampled from 12 states across Nigeria between February 2013 and November 2015.

Methodology: Morphological traits were measured according to the FAO description. Nearest neighbor analyses (hierarchical cluster) were done using SPSS 23.0 version.

Results: The nearest neighbor analyses showed that higher degree of relatedness exists between the wild type chicken and the frizzle feather indigenous chicken type in Nigeria. Traits interdependence was observed between and among the different morphological traits within the different poultry species.
\end{abstract}


Conclusion: The characters measured could be of useful genetic importance that may play significant role as markers for selection or breeding programs for improved productivity under free range or scavenging feed resource-based production systems.

Keywords: Morphology; poultry; indigenous; traits-interdependence.

\section{INTRODUCTION}

Poultry plays great role in food security (animal protein) in most part of the world. The indigenous domesticated birds are said to cover over $60 \%$ of the world's total poultry population in most Africa nations [1]. In Nigeria, they are mostly found and reared by the rural populations in the rural home sets harnessing the birds for meat and income sources $[1,2]$. These local indigenous poultry species have been identified to possess traits of great economic interest and values: they are hardy, show great ability in resisting certain avian diseases or pathogens and require less attention on feed quality demand [2-4]. These local poultry types are a great source of genetic reservoir for particularly genes that confer ability to adapt to the tropical and subtropical regions $[1,5]$.

Variations have been reported to exist among poultry populations and types. The variations come in many different forms, genetic and morphological makeup consisting of high important differences. Furthermore, traits interdependence in poultry species has been reported [3,6-8]. Adekoya [2] stated that traits interaction exists within indigenous chicken types and observable relatedness between and among the chicken types. Significant sexual dimorphism in the body measurements between both sexes of muscovy duck in the ecotypes studied and low to high correlation between traits has also been reported by Ogah [7].

The understanding of the diverse morphological differences and the relationship which may exist provide valuable information on the poultry genetic reservoir: variations within and among different populations and types. Sustainable management, characterization, conservation and use of indigenous poultry is a necessity for increased and large scale poultry production, poverty alleviation, proper breeding programs and schemes, national development and global food security [9]. Variations within populations can be established or estimated using analytical packages such as the multifactorial analyses to analyze the morphological traits present within the population. Cluster analysis can show relatedness and or dissimilarity within and among items of a data set [10].

The present study aimed at examining the degree of relatedness among three indigenous chicken types: wild type, naked neck and frizzle feather, and the interdependence between and among morphological traits in the indigenous chicken, duck and guinea fowl populations.

\section{MATERIALS AND METHODOLOGY}

\subsection{Study Location}

The sampled locations include the following states in Nigeria: Lagos, Ogun, Oyo, Osun and Kwara (South-West), Akwa-lbom, Edo (SouthSouth), Imo, Anambra and Enugu (South-East), Taraba, (North-East) and Benue (North central) states (Fig. 1).

\subsection{Study Population}

A total of 429 indigenous birds of reproducing age: 247 chickens (96 wild type, 79 naked neck and 72 frizzle feather), 81 ducks and 101 guinea fowl were used for the study (Fig. 2).

\subsection{Morphological Traits Measured}

Ten qualitative and ten quantitative traits in each bird type were considered based on FAO description [10-12]: Quantitative traits measured in chicken include height, shank length, back length, beak length, comb length, spur number, wattle size, toe number, wing length and tail length. Qualitative traits measured in chicken include skin color, feet feather, beak color, shank color, feather distribution, comb type, feather morphology, eye color, tail color and plumage color. Quantitative traits measured in guinea fowl include height, back length, shank length, wing length, tail length, beak length, toe number, spur number, helment length and wattle size. Qualitative traits measured in guinea fowl include eye color, helment color, feather morphology, skin color, shank color, tail color, neck color, plumage color, head-cap color and beak color. Quantitative traits measured in duck include height, wing length, back length, tail length, neck 
length number of toes, foot length, shank length and beak length. Qualitative traits measured in duck include feather distribution, skin color, feet feather, caruncle, feather distribution, shank color, tail color, plumage color, eye color and bill color.

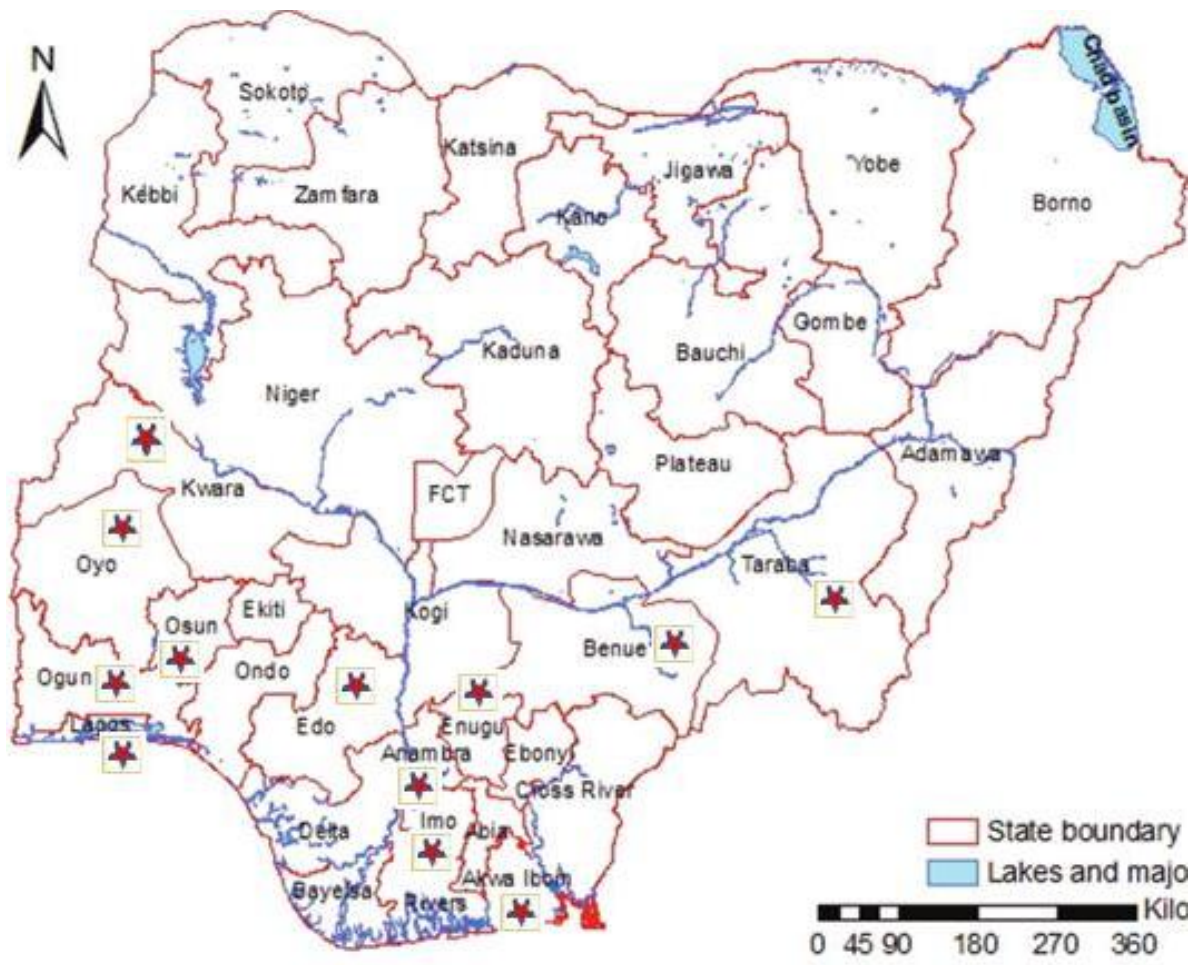

Fig. 1. Sampled locations (states) in Nigeria $(\underset{\psi}{)}$

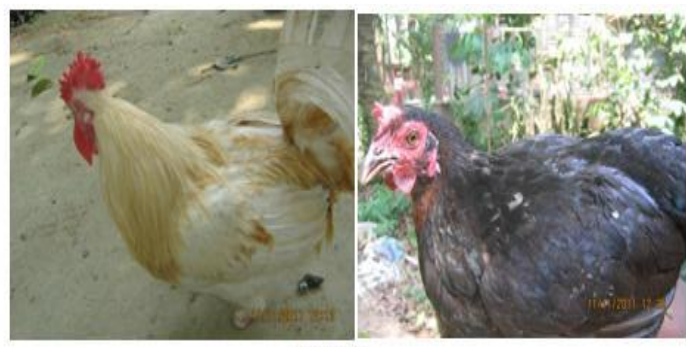

Wild type

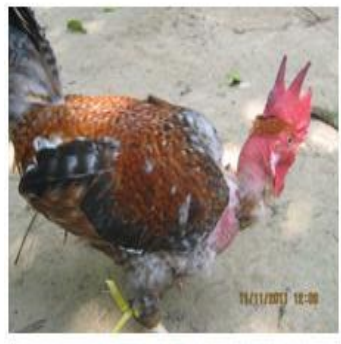

Naked neck

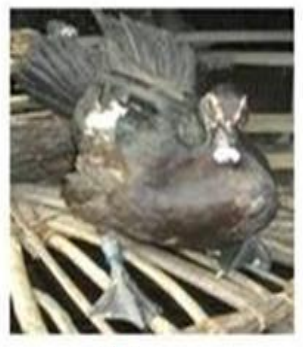

Duck

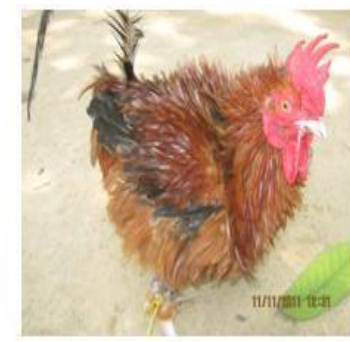

Frizzled feather

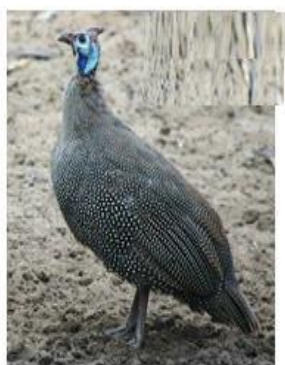

Guinea fowl

Fig. 2. The different indigenous birds studied 


\subsection{Statistical Analyses}

Nearest neighbor analyses (hierarchical cluster) were done using SPSS 23.0 version.

\section{RESULTS}

The result demonstrated that some degree of relatedness and non-relatedness exist among the three indigenous chicken types investigated based on the morphological data. Closer relatedness was observed to exist between the wild type chicken and the frizzle feather chicken type with the naked neck chicken type at a distance. Furthermore, traits interdependence were observed to exist between and among some traits investigated in all the indigenous poultry species:

\subsection{Relatedness among Three Indigenous Chicken Types}

Strong relatedness/similarities exist between the wild type chicken and frizzled feather indigenous chicken populations, however, the naked neck indigenous chicken type was distantly related (Fig. 3).

\subsection{Morphological Traits Interdependence}

\subsubsection{Chickens}

Within the indigenous chicken population the back length, wing length and tail length formed a cluster. Shank length, beak length and comb length showed more relationship while the height was distinctly separated from the other traits (Fig. 4). The qualitative traits skin color, shank color and beak color formed a cluster but showed less relationship with eye and tail colors (Fig. 5).

The wild type and frizzled feather indigenous chicken populations showed more similarity but the naked neck type distantly related (Fig. 3).

Within the chicken population comb length and the beak length formed a cluster $(0.96$ coefficient level) while the wing length, back length and tail length cluster (0.93 coefficient level) (Fig. 4).

At 0.96 coefficient level skin color, beak color, shank color, comb type and feather morphology showed strong interaction while the plumage color was distinctly separated (Fig. 5).

\subsubsection{Guinea fowls}

Trait interdendepence at 0.96 coefficient level among wattle length, helment length and beak length showed strong morphological trait interaction. Tail lenghth, wing length and shank length also showed some traits interdependence by clustering together to form a sub cluster while the wing length, tail length and shank length formed a cluster (Fig. 6). Among the qualitative traits measured the skin, shank, eyes and helmet colors formed a sub cluster (Fig. 7).

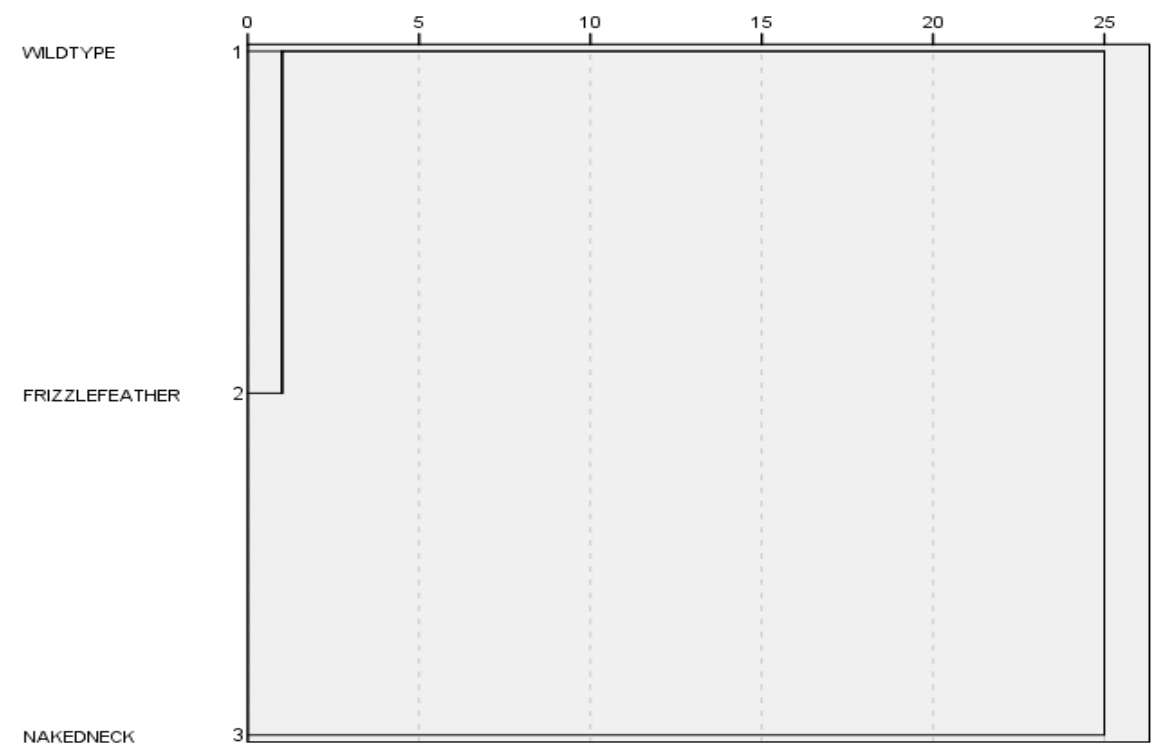

Fig. 3. Closest neighbor relatedness among 3 indigenous chicken types 


C A S E
LabEI
COMBLENG
SPURNUMB
BEAKLENG
SHANKLEN
WATTLESI
TOENUMBE
WINGLENG
TAILLENG
BACKLENG
HEIGHT

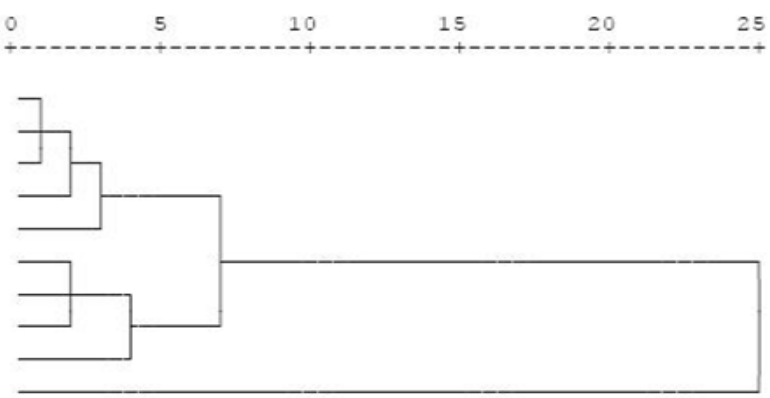

Fig. 4. Interdependence among quantitative traits within the chicken population

CA S E
Label
skincolo
feetfeat
beakcolo
Shankcol
Featherd
Combtype
Featherm
eyecolou
Tailcolo
plumagec

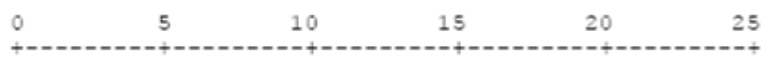

Fig. 5. Degrees of interdependence among qualitative traits within the chicken population

$$
\begin{aligned}
& \text { CA A E } \\
& \text { Label } \\
& \text { wattlesi } \\
& \text { helment1 } \\
& \text { spurnumb } \\
& \text { toenumbe } \\
& \text { beakleng } \\
& \text { tailleng } \\
& \text { wingleng } \\
& \text { shanklen } \\
& \text { backleng } \\
& \text { height }
\end{aligned}
$$

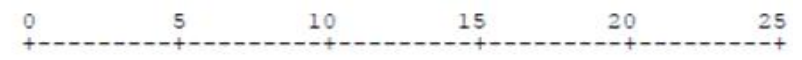

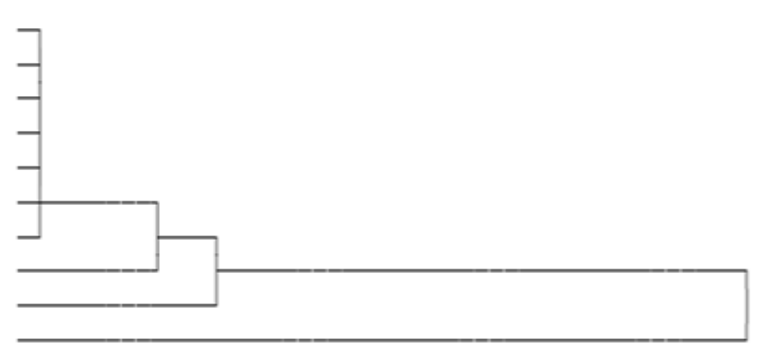

Fig. 6. Dendrogram of quantitative traits interdependence within guinea fowl

$$
\begin{aligned}
& \text { C A S E } \\
& \text { Label } \\
& \text { eyecolor } \\
& \text { helmetco } \\
& \text { featherm } \\
& \text { skincolo } \\
& \text { shankcol } \\
& \text { tailcolo } \\
& \text { neckcolo } \\
& \text { plumagec } \\
& \text { headcapc } \\
& \text { beakcolo }
\end{aligned}
$$

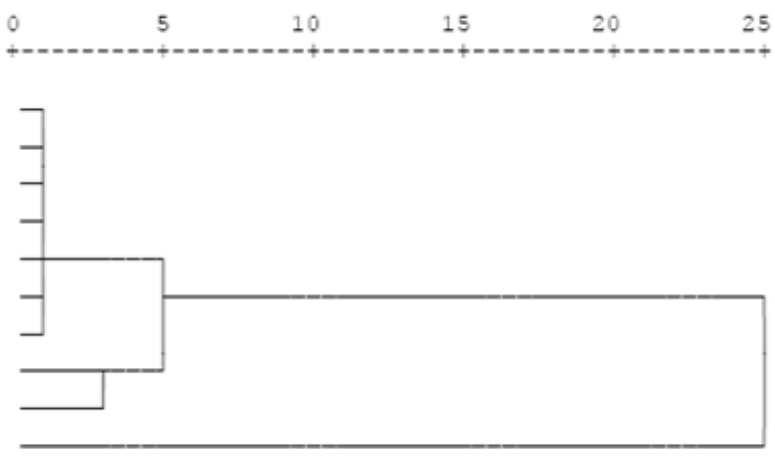

Fig. 7. Degree of relatedness based on qualitative traits measurments within the guinea fowl 


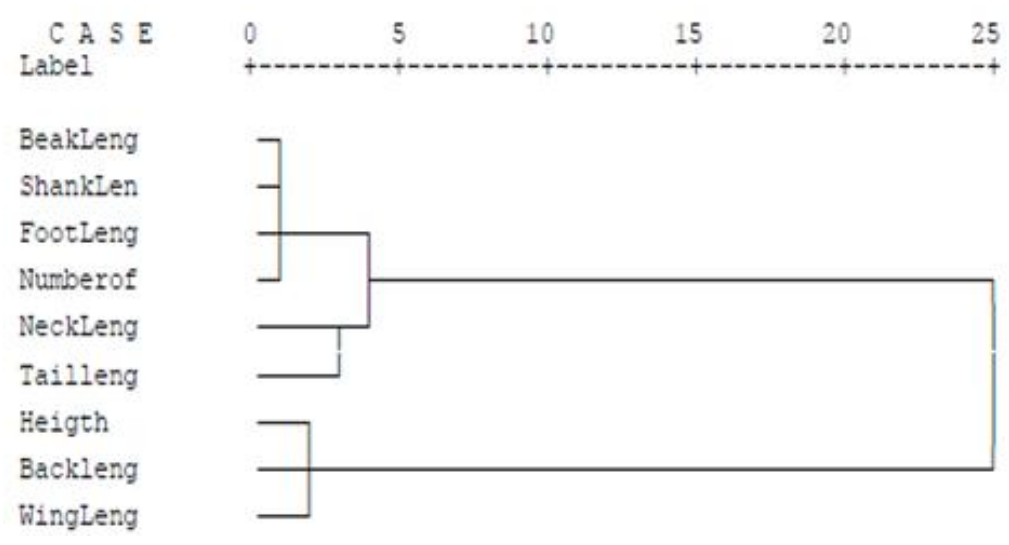

Fig. 8. Dendrogram of qualitative traits interdependence within the ducks

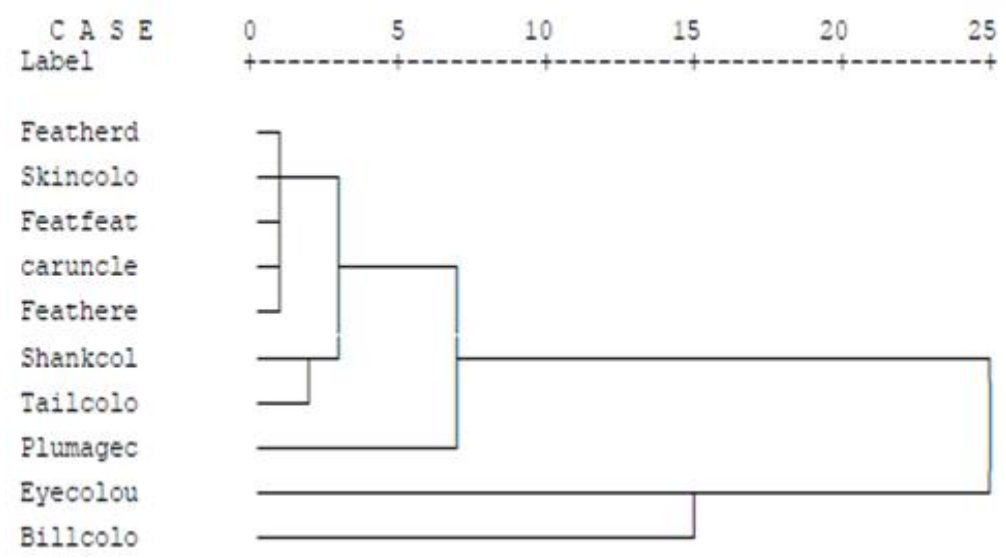

Fig. 9. Degree of relatedness based on qualitative traits measurements within the ducks

\subsubsection{Ducks}

Among the ducks beak length, shank length and foot length made a sub cluster $(0.96$ coefficient level) while the height, back length and wing length made sub cluster (0.92 coefficient level) (Fig. 8).

The skin color, feather distribution, caruncle, shank color and tail color ( 0.92 coefficient level) clustered together. However, the eye and bill colors were distinctly separated from the other morphological features (Fig. 9).

\section{DISCUSSION}

Genetic characteristics are expressed as phenotypes with influence from the environment. These expressions are often altered by variations in both the genetic compositions and the environment; some traits classified complex traits while some are controlled by single gene [13]. In the present study the wild and frizzle feather indigenous chicken types showed more relatedness among the three indigenous chicken types. This suggested closer ancestral line between the indigenous wild and frizzle feather chicken types than with the naked neck. This observation is consistent with the finding of Adekoya [2]. It also agrees with Mogesse [3] who reported some degree of relatedness existing among some local chicken types in Ethiopia. Our report also agrees with the report from Musa [14] which revealed that relatedness exists among the three indigenous chicken types In Nigeria.

Furthermore, Nigussie [15] reported heterogeneity in most morphological, phenotypical traits, and phenotypic diversity within indigenous chicken populations. The dendrograms in this report showed the existence of diversity in the morphological features of Nigeria indigenous chicken populations. This report, therefore, highlights the rich and diverse 
genetic reservoir present within the indigenous poultry population. Hence calls for proper conservation of these rich genetic materials before they are eroded. The population may, therefore, possess useful genetic traits that could be employed during selection or breeding programs for improved productivity under free range or scavenging feed resource-based production systems.

Naked neck and feather morphology and to some extent wattle size within the chicken population showed high heritability with high genetic advance. In the chicken population height was distinctly separated from all other traits. Back, tail and wing lengths also showed strong interdependence in the chickens. The shank length also showed some degree of interdependence with back, tail and wing lengths in the chickens. Furthermore, within both the chicken population beak length and wattle size often clusters together. Interdependence and or intermingling of morphological traits have also been reported by Malek [16].

Height in the guinea fowls was also distinctly separated from all other traits. Back, tail and wing lengths also showed strong interdependence within the guinea fowls. The shank length also showed some degree of interdependence with back, tail and wing lengths in guinea fowls. Beak length and wattle size also clustered together similar to what was observed within the chicken population. These may be indications that the traits may be interdependent. The report of Ogah [17] revealed that trait interdependence and or intermingling exist between and among certain morphological traits in guinea fowls. The finding in this report may therefore, suggest that height may not have hereditary correlation with the other morphological traits in both chickens and guinea fowls.

In ducks, however, height showed strong relation with back and wing lengths. Also the shank length, beak length and tail length showed some intermingling. Our report agrees with the report of Ogah [7] that reported correlation between morphological traits, though with varied degree of interdependence between different traits. The report added that the correlation and variations among the traits may also indicate adaptability to the varied environments.

Furthermore, shank, skin, eye, beak colors and feather distribution indicated some degree of interdependence in the chickens. Similar observation was seen among the guinea fowls except the beak color which was distinctly separated from other traits. Among the ducks however, shank, skin colors and feather distribution were within the same cluster which may also indicate trait interdependence. Adedibu [10] reported positive relationship among some morphological traits among helmeted guinea fowls in Kaduna. Yakubu and Ugbo, [4] revealed that diversity and trait independence exist in the duck's morphological trait as revealed in their study on duck populations from the guinea savannah and rainforest zones of Nigeria. They added that although morphological variation is present the studied populations might have descended from a common ancestral line or population.

These findings may be indications that the morphological traits influence or interact with one another's expression. Morphological traits interdependence has been reported by Ajayi [18]. They added that the relationship observed among the morphological features is of significance in management, characterization and conservation of the genetic resources in this bird type. Direct and indirect correlation and trait interdependence between morphological traits have been reported $[7,10,16]$.

These characters, based on the relationship displayed, showed the possibility of having direct effect on one another, and direct selection may be more effective towards the improvement of yield in the poultry. Furthermore, observed morphological and phenotypical variations that have economic values have been reported among the indigenous chicken populations in different parts of the globe especially Africa [3, 10,19-21]. It is pertinent therefore in-depth molecular studies be done to evaluate the level of genetic differentiation and relationship present within these morphological features among the different indigenous poultry species with the aim of aiding global food security and the conservation of the genetic resources before they are eroded.

\section{CONCLUSION}

The present study revealed that rich morphological traits diversity exists within the Nigeria indigenous chicken population. It also showed that morphological traits interdependence exist between and among each other. These traits are of economic importance and values and could be employed as selection 
markers during breeding programs. Therefore, the findings of this study in combination with molecular marker assisted selection could be applied by developing countries towards developing indigenous poultry types with improved traits of interest and can serve as baseline information for conservation programs.

\section{COMPETING INTERESTS}

Authors have declared that no competing interests exist.

\section{REFERENCES}

1. FAO. Statistical database of food and agriculture organization of the United Nations, Rome. Italy; 2000.

2. Adekoya KO, Abazuh UD, Bankole KA, Oboh BO. A comparative morphological characterization of three local and three exotic chicken types in Nigeria. Unilag J Med Sci Technol. 2013;1(1):87-96.

3. Mogesse $\mathrm{HH}$. Phenotypic and genetic characterization of indigenous chicken population in Northwest Ethiopia. PhD, University of the Free State, South Africa; 2007.

4. Yakubu, Ugbo SB. An assessment of biodiversity in morphological traits of muscovy ducks in Nigeria using discriminant analysis. Int Conf Biol Environ Chem. 2010;1(2011):389-391.

5. Horst $P$. Native fowls as reservoir for genomes and major genes with direct and indirect effects on adaptability and their potential for tropical oriented breeding plans. Anim Breed Abstract. 1989;53: 13-23.

6. Ladokun AO, Yakubu A, Otite JR, Omeje JN, Sokunbi OA, Onyeji E. Haematological and serum biochemical indices of naked neck and normally feathered Nigerian indigenous chickens in a sub humid tropical environment. Int J Poult Sci. 2008; 7(1):55-58.

7. Ogah M. Analysis of morphological traits of geographically separated population of indigenous muscovy duck (Cairina moschata). Int J Poult Sci. 2009;8(2): 179-182.

8. Ige $A O$, Salako AE. Transferrin genetic types in fulani and yoruba ecotype of Nigeria indigenous chickens. Iranian J Appl Anim Sci. 2014;4(1):191-196.

9. INFPD/FAO/IFAD. Opportunities of poultry breeding programs for family production in developing countries: The bird for the poor.
Proceedings of an E-conference Held; 2011.

10. Adedibu II, Ayorinde KL, Musa AA. Multifactorial analyses of morphological traits of extensively reared helmeted guinea fowls Numidia meleagris in Kaduna and Kastina States of Nigeria. Brit $\mathrm{J}$ AppISci Technol. 2014;4(25):3644-3652.

11. Adekoya $\mathrm{KO}$, Oboh $\mathrm{BO}$, Adefenwa MA, Ogunkanmi LA. Morphological characterization of five Nigerian Indigenous chicken types. J Sci Res Develop. 2013;14:55-66.

12. Fajemilehin SK. Morphological characteristics of three varieties of greybreasted helment guinea fowl in Nigeria. Int J Morphol. 2010;28(2): 557-562.

13. Klug WS, Cummings MR, Spencer CA, Palladino MA. Concept of genetics. $9^{\text {th }}$ edition. Pearson Education, Incoporation, publishing as Pearson Benjamin Cummings, 1301 Sansome St., San Francisco, CA 94111; 2009.

14. Musa AA, Abdulmalik SE, Shoyombo AJ, Akinsola OM, Usman T. Morphological characterization of Nigerian chicken genotypes using multivariate analyses. Int J Poult Sci. 2018;17:560-567.

15. Nigussie $\mathrm{H}$, Kebede $\mathrm{K}$, Ameha $\mathrm{N}$. Phenotypic and morphological characterization of indigenous chicken populations in Southern Zone of Tigray, Ethiopia. J Biol Agric Healthc. 2015;5(21): 132-141.

16. Malek MA, Rafii MY, Afroz SS, Nath UK, Mondal MA. Morphological characterization and assessment of genetic variability, character association, and divergence in soyabeans mutants. Sci World J; 2014.

[Article ID 968796:12]

Available:http://dx.doi.org/10.1155/2014/96 8796

17. Ogah DM. Variability in body shape characters in an indigenous guinea fowl (Numida meleagris L.). Slovak J Anim Sci. 2013;46(3):100-114.

18. Ajayi OO, Adeleke MA, Sanmi TM, Yakubu A, Peters SO, Imumori IG, Ozoje MO, Ikeobi NC, Adebambo OA. Application of principal component and discriminate analyses to morpho-structral indices of indigenous and exotic chickens raised under intensive management system. Trop Anim Health and Prod. 2012;44(4): 675-684. 
19. Ajayi FO. Nigerian indigenous chicken: $A$ valuable genetic resource for meat and egg production. Asian J Poult Sci. 2010; 4(4):164-172.

20. Olawunmi O, Salako AF, Afuwape AA. Morphometric differentiation and assessment of function of the fulani and yoruba ecotype indigenous chickens of Nigeria. Int J Morphol. 2008;26(4):975-980.
21. Khobondo JO, Muasya TK, Miyumo S, Okeno TO, Wasike CB, Mwakubambanya R, Kingori AM, Kahi AK. Genetic and nutrition development of indigenous chicken in Africa. Livestock Research for Rural Development. 2015;27(122).

[Retrieved February 6, 2017] Available:http://www.Irrd.org//rrd27/7/khob2 7122.html

(c) 2019 Abazuh et al.; This is an Open Access article distributed under the terms of the Creative Commons Attribution License (http://creativecommons.org/licenses/by/4.0), which permits unrestricted use, distribution, and reproduction in any medium, provided the original work is properly cited.

Peer-review history:

The peer review history for this paper can be accessed here: http://www.sdiarticle4.com/review-history/48045 